\title{
Comparison of outcome in 1809 patients treated with drug-eluting stents or bare-metal stents in a real-world setting
}

This article was published in the following Dove Press journal:

Vascular Health and Risk Management

2I November 20II

Number of times this article has been viewed

\author{
Alexander Vogt' \\ Anke Schoelmerich' \\ Franziska Pollner \\ Manuela Schlitt' \\ Uwe Raaz' \\ Lars Maegdefessel ${ }^{2}$ \\ Iris Reindl' \\ Michael Buerke' \\ Karl Werdan' \\ Axel Schlitt ${ }^{\prime}$ \\ 'Department of Medicine III, Martin \\ Luther-University, Halle, Germany; \\ ${ }^{2}$ Division of Cardiovascular Medicine, \\ Stanford University School of \\ Medicine, Stanford, CA, USA
}

Purpose: The aim of this study was to determine the long-term safety of drug-eluting stent (DES) versus bare metal stent (BMS) implantation in a "real-world" setting.

Patients and methods: A total of 1809 patients who were treated with implantation of either BMS or DES were assessed. Kaplan-Meier and multivariate Cox regression analyses concerning primary endpoint of cardiac mortality were performed.

Results: A total of 609 patients received DES. Mean age was $66.2 \pm 11.3$ years, $69.4 \%$ were male, and $1517(83.8 \%$ ) were treated for acute coronary syndrome (unstable angina 510 [28.2\%], non-ST-elevation myocardial infarction [NSTEMI] 506 [28.0\%], and ST-elevation myocardial infarction [STEMI] 501 [27.7\%]). Mean follow-up was $34 \pm 15$ months. During follow-up, 268 patients died of cardiac causes (DES 42 [7.3\%]; BMS $226[19.6 \%] ; P<0.001$ ). Univariate Kaplan-Meier analysis showed an advantage of DES over BMS concerning the primary endpoint $(P<0.001)$. When adjusting for classic risk factors and additional factors that affect the progression of coronary heart disease (CHD), DES was not found to be superior to BMS (hazard ratio $0.996,95 \%$ confidence interval $0.455-2.182, P=0.993$ ). Severely impaired renal function was an independent predictor for cardiac mortality after stent implantation.

Conclusion: Treatment with DES is safe in the long term, also in patients presenting with STEMI. However, in multivariate analyses it is not superior to BMS treatment.

Keywords: coronary stent, outcome, renal insufficiency, myocardial infarction, STEMI

\section{Introduction}

Stent implantation has been established as a safe and effective method of treating coronary heart disease (CHD) ${ }^{1,2}$ Several clinical trials investigating the safety and efficacy of drug-eluting stents (DES) versus bare metal stents (BMS) showed an advantage of DES over BMS concerning restenosis..$^{3-5}$ Since being introduced into clinical practice in 2003, DES have been increasingly used in patients with stable and unstable $\mathrm{CHD}^{6}$

Late stent thrombosis as a fatal event 12 or more months after DES implantation is associated with a mortality of up to $45 \%$, 7 and represents a major concern. Therefore, the long-term safety of DES has been extensively discussed in the past several years. Various authors reported an increasing incidence of cardiac death related to DES implantation. ${ }^{9-11}$ One of the main reasons for the increase in cardiac and cardiovascular mortality after DES treatment seems to be the fact that patient populations in these trials are highly selected and, thus, applying the findings to "real-world" use has limitations.
Correspondence: Alexander Vogt Department of Medicine III, Martin Luther-University, Ernst-Grube-Str 40, 06120 Halle, Germany

Tel +49345 5572017

Fax +49345 557495 I

Email alexander.vogt@medizin.uni-halle.de 
The aim of this study, therefore, was to determine the safety of DES versus BMS implantation in a "real-world" setting.

\section{Patients and methods}

\section{Patients, demographic, clinical,} and angiographic data

A total of 2056 CHD patients in whom a percutaneous coronary intervention (PCI) was performed with implantation of a BMS or DES at the Department of Medicine III, Martin Luther-University Halle-Wittenberg between 2004 and 2006 were retrospectively assessed. Inclusion criterion was the implantation of a DES or BMS. Exclusion criteria included balloon dilatation without stent implantation or unsuccessful PCI and the decision for solely medical treatment. The choice of stent type was up to the interventional cardiologist based on national and international guidelines and recommendations. Thus, DES were more frequently used in patients with stable or unstable angina in native vessels, whereas BMS were more frequently implanted in patients presenting with acute myocardial infarction and more complicated lesions (ie, bifurcational or ostial lesions, unprotected left main). ${ }^{7}$ In case a patient received both stent types during the hospital stay, she/he was assigned to the drug-eluting stent cohort. PCI during a prior hospital stay was not considered in this analysis.

Data were collected concerning admission diagnosis (stable angina [SAP], unstable angina [UAP], non-STelevation myocardial infarction [NSTEMI], ST-elevation myocardial infarction [STEMI]), bodyweight, height, medical history, classic risk factors (family history of CHD, diabetes mellitus, hyperlipidemia, hypertension, and current smoking), history of transient ischemic attacks (TIA) or stroke, current medication, duration of hospital stay, laboratory test results, and angiographic data. Left ventricular ejection fraction was measured by routinely performed echocardiography.

In-hospital adverse events included cardiac and noncardiac death, myocardial infarction, stroke/TIA, rePCI, operative revascularization, and acute renal failure. Bleeding complications were recorded as puncture site bleeding, hematoma, aneurysm, arteriovenous fistula, gastrointestinal bleeding, intracranial bleeding, and minor bleeding complications (not related to puncture site, eg, epistaxis).

Primary endpoint was death from cardiac causes. This information was (as described in the following) obtained from electronic patient files, physicians, relatives, and civil registration offices.

\section{Follow-up}

For acquiring follow-up data a standardized questionnaire was sent out, which included questions concerning adverse events such as hospital admission, re-PCI or surgical coronary revascularization, bleeding complications, and thromboembolic events. If the patients did not send back the questionnaires, a telephone interview was conducted with the patient or his/her relatives or the patient's physician was contacted. If this information could not be obtained from these persons, civil registration offices were contacted and information was requested about current address or date of death. The study was approved by the ethics committee of the Martin Luther-University Halle-Wittenberg.

\section{Statistical analyses}

Continuous variables were described as mean and standard deviation; skewed variables as median and $25 \%$ and $75 \%$ quartiles. Categorical variables were documented as a percentage. For comparison of metric, normally distributed variables, $t$-test was used. Mann-Whitney U-test was used to compare skewed variables. For normally distributed, categorical variables, the chi-square test was employed. Survival analyses included Kaplan-Meier analyses with log-rank test and multivariate Cox regression analyses. Multivariate Cox regression was applied to analyze the influence of DES on the primary endpoint, which included the classic risk factors (gender, body mass index, current smoking, diabetes mellitus, hypertension, hyperlipidemia, and family history of CHD) and additional factors affecting prognosis after stent implantation (age, hemoglobin, C-reactive protein, low density lipoprotein [LDL] cholesterol, glomerular filtration rate, and left ventricular ejection fraction).

$P$-values $<0.05$ were considered significant. Statistical analyses were performed using SPSS Statistics (SPSS Inc, Chicago, IL) software.

\section{Results}

\section{Patient characteristics}

Of the 2056 patients, 1809 individuals met the inclusion criteria: 609 patients received DES, and 1200 received BMS. At the time of admission to the hospital, the mean age was $66.2 \pm 11.3$ years; patients treated with DES were significantly younger than patients treated with BMS $(60.9 \pm 11.4$ versus $68.9 \pm 10.2$ years, $P<0.001$ ). Of the patients, $69.4 \%$ were male $(73.6 \%$ in the DES group versus $67.2 \%$ in the BMS group $(P=0.007)$ (Table 1$)$.

The two groups also differed significantly regarding other cardiovascular risk factors: the prevalence of diabetes 
Table I Baseline characteristics, admission diagnosis, and number of diseased vessels

\begin{tabular}{|c|c|c|c|c|}
\hline Variable & $(n=1809)$ & DES $(n=609)$ & BMS $(n=I 200)$ & $P$-value \\
\hline Age, mean (SD) & $66.2( \pm 11.3)$ & $60.9( \pm 11.4)$ & $68.9( \pm 10.2)$ & $<0.001$ \\
\hline Male, n (\%) & $1255(69.4)$ & $448(73.6)$ & $807(67.2)$ & 0.007 \\
\hline \multicolumn{5}{|l|}{ Medical history, n (\%) } \\
\hline Current smoker & $410(22.8)$ & $169(27.8)$ & $24 I(20.2)$ & $<0.001$ \\
\hline Diabetes mellitus & $631(35.0)$ & $168(27.6)$ & $463(38.6)$ & $<0.001$ \\
\hline Hypertension & $1312(72.5)$ & $422(69.3)$ & $890(74.2)$ & 0.020 \\
\hline Hyperlipidemia & $657(36.3)$ & $249(40.9)$ & $408(34.0)$ & 0.005 \\
\hline Family history & $392(21.7)$ & $183(30.0)$ & $209(17.4)$ & $<0.001$ \\
\hline Coronary heart disease & $655(36.1)$ & $230(37.8)$ & $425(35.4)$ & 0.326 \\
\hline Peripheral artery disease & $137(7.6)$ & $37(6.1)$ & $100(8.4)$ & 0.087 \\
\hline Myocardial infarction & $400(22.1)$ & 127 (20.9) & $273(22.8)$ & 0.358 \\
\hline Previous $\mathrm{PCl}$ & $321(17.7)$ & $118(19.4)$ & $203(16.9)$ & 0.193 \\
\hline Ejection fraction, mean (SD) & $54( \pm 15)$ & $58( \pm 15)$ & $52( \pm 16)$ & $<0.001$ \\
\hline BMI, mean (SD) & $28.2(4.5)$ & $28.0(4.6)$ & $28.2(4.5)$ & 0.389 \\
\hline \multicolumn{5}{|l|}{ Admission diagnosis, $\mathrm{n}(\%)$} \\
\hline SAP & $258(14.3)$ & $121(19.9)$ & | 37 (| | .4) & $<0.001$ \\
\hline UAP & $510(28.2)$ & $198(32.5)$ & $312(26.0)$ & 0.003 \\
\hline NSTEMI & $506(28.0)$ & $154(25.3)$ & $352(29.3)$ & 0.058 \\
\hline STEMI & $50 \mathrm{I}(27.7)$ & $126(20.7)$ & $375(3 \mid .2)$ & $<0.001$ \\
\hline Other & $34(1.9)$ & $10(1.6)$ & $24(2.0)$ & 0.394 \\
\hline \multicolumn{5}{|l|}{$\mathrm{n}$ vessel disease, $\mathrm{n}(\%)$} \\
\hline 1 & $402(22.2)$ & $157(25.8)$ & $245(20.4)$ & 0.006 \\
\hline 2 & $579(32.0)$ & $194(31.9)$ & $385(32.1)$ & 0.939 \\
\hline 3 & $828(45.8)$ & $256(42.0)$ & $572(47.7)$ & 0.028 \\
\hline $\mathrm{GFR}, \mathrm{mL} / \mathrm{min}$ & $76(56 / 101)$ & $90(66 / 1 / 2)$ & $70(52 / 94)$ & $<0.001$ \\
\hline LDL cholesterol, mmol/L & $3.32( \pm \mid .2)$ & $3.46( \pm 1.25)$ & $3.23( \pm 1.18)$ & 0.019 \\
\hline $\mathrm{HDL}$ cholesterol, $\mathrm{mmol} / \mathrm{L}$ & $1.0(0.8 / 1.2)$ & $1.0(0.8 / 1.2)$ & $0.9(0.8 / 1.2)$ & 0.007 \\
\hline WBC, Gpt/L & 8.94 (7.0/II.7) & $8.5(6.79 / 10.56)$ & $9.24(7.13 / 12.28)$ & $<0.001$ \\
\hline Hemoglobin, mmol/L & $8.6( \pm 1.16)$ & $8.8( \pm 1.0)$ & $8.5( \pm 1.2)$ & $<0.001$ \\
\hline $\mathrm{CRP}, \mathrm{mg} / \mathrm{L}$ & $5.2(5 / / 5)$ & $5.0(5.0 / 9.1)$ & $6.2(5.0 / 20.2)$ & $<0.001$ \\
\hline \multicolumn{5}{|c|}{ Medication at hospital admission, n (\%) } \\
\hline DAP & $227(12.5)$ & $84(13.8)$ & $143(12.0)$ & 0.540 \\
\hline Aspirin & $589(35.6)$ & $206(33.8)$ & $383(32.0)$ & 0.889 \\
\hline Clopidogrel & $8 \mathrm{I}(4.5)$ & $31(5.1)$ & $50(4.2)$ & 0.553 \\
\hline Beta-blocker & $932(5 \mid .5)$ & $328(53.9)$ & $604(50.3)$ & 1.000 \\
\hline ACEI & $676(37.4)$ & $219(36.0)$ & $457(38.1)$ & 0.055 \\
\hline ARB & $206(11.4)$ & $75(12.3)$ & $132(\mid 1.0)$ & 0.739 \\
\hline $\mathrm{CCB}$ & $217(12.0)$ & $72(11.8)$ & $146(12.2)$ & 0.480 \\
\hline Diuretic agents & $566(31.3)$ & $163(26.8)$ & $403(33.6)$ & $<0.001$ \\
\hline Statins & $608(33.6)$ & $230(37.8)$ & $378(31.5)$ & 0.088 \\
\hline OAC & $118(6.5)$ & $40(6.6)$ & $78(6.5)$ & 0.766 \\
\hline \multicolumn{5}{|l|}{ Medication at discharge, n (\%) } \\
\hline DAP & $1623(90.2)$ & $571(93.8)$ & 1052 (87.7) & 0.570 \\
\hline Aspirin & $33(1.8)$ & $14(2.3)$ & $19(1.6)$ & 0.369 \\
\hline Clopidogrel & $30(1.7)$ & $9(1.5)$ & $21(1.8)$ & 0.560 \\
\hline Beta-blocker & I543 (85.3) & $552(90.6)$ & 991 (82.6) & 0.056 \\
\hline ACEI & |37| (75.8) & $470(77.2)$ & 901 (75.I) & 0.180 \\
\hline ARB & $24 \mid(\mid 3.3)$ & $86(14.1)$ & $155(13.0)$ & 0.824 \\
\hline $\mathrm{CCB}$ & 207 (II.4) & $69(11.3)$ & | 38 (I I.5) & 0.641 \\
\hline Diuretic agents & $1009(55.8)$ & $293(48.1)$ & $716(59.7)$ & $<0.001$ \\
\hline Statins & 1422 (78.6) & $506(83.1)$ & $916(76.3)$ & 0.209 \\
\hline OAC & $96(5.3)$ & $33(5.4)$ & $63(5.3)$ & 0.885 \\
\hline
\end{tabular}

Note: Values are percentages or mean \pm SD, given in SI units.

Abbreviations: $\mathrm{PCl}$, percutaneous coronary intervention; SAP, stable angina pectoris; UAP, unstable angina pectoris; NSTEMI, non-ST-segment elevation myocardial infarction; STEMI, ST-segment elevation myocardial infarction; LDL, low density lipoprotein; HDL, high density lipoprotein; GFR, glomerular filtration rate; WBC, white blood cell count; CRP, C-reactive protein; DAP, dual antiplatelet therapy; ACEI, angiotensin-converting enzyme inhibitor; ARB, angiotensin receptor blocker; CCB, calcium channel blocker; OAC, oral anticoagulation. 
mellitus $(27.6 \%$ versus $38.6 \%, P<0.001)$ and hypertension (69.3\% versus $74.2 \%, P=0.020)$ was significantly higher in patients treated with BMS, whereas a positive family history of CHD (30.0\% versus $17.4 \%, P<0.001)$, current smoking (27.8\% versus $20.2 \%, P<0.001)$, and hyperlipidemia (40.9\% versus $34.0 \%, P=0.005$ ) was found more often in patients treated with DES (Table 1).

The mean left ventricular ejection fraction was $>50 \%$ in both groups; however, it was significantly lower in the BMS group $(52 \% \pm 16 \%$ BMS versus $56 \% \pm 15 \%$ DES, $P<0.001$ ) (Table 1).

Interestingly, the two groups did not differ significantly regarding the medication at admission to the hospital and at discharge, except for the use of diuretic agents, which were used more frequently in the BMS group.

\section{Indication for hospital admission}

A total of $258(14.3 \%)$ patients suffered from stable angina, and 1517 (83.9\%) suffered from acute coronary syndrome (unstable angina 510 [28.2\%], NSTEMI 506 [28.0\%], and STEMI 501 [27.7\%]). In the DES group, the rate of stable angina was significantly higher than in the BMS group (19.9\% versus $11.4 \%, P<0.001)$. Unstable angina and STEMI were found more often in the BMS group, whereas NSTEMI did not differ between the two groups (Table 1).

\section{Laboratory results}

Markers of inflammation (C-reactive protein and white blood cell count) were slightly, but significantly different in the two groups (Table 1). Further prognostically relevant parameters, ${ }^{12,13}$ ie, hemoglobin and LDL cholesterol, were within normal range in the group as a whole. Nevertheless, the mean value of these parameters was slightly higher in the DES group than in the BMS group. The glomerular filtration rate, calculated via the Cockroft-Gault formula, was significantly decreased in the BMS group. Table 1 shows the details for these markers.

\section{In-hospital adverse events}

The median duration of hospital stay was 7 (4/11) days (DES 6 [3/9] versus BMS 8 [6/12], $P=0.042)$. In-hospital cardiac (5.7\% versus $0.5 \%, P=0.035)$ and in-hospital noncardiac death $(1.1 \%$ versus $0.2 \%, P<0.001)$ occurred more frequently in the BMS than in the DES group. The results were similar regarding incidence of myocardial infarctions (DES $0.3 \%$ versus BMS $1.3 \%, P=0.042$ ). Bleeding complications were observed more frequently in the BMS cohort than in the DES cohort, especially gastrointestinal and minor bleedings.

\section{Follow-up and survival analyses}

Follow-up data concerning the primary endpoint of cardiac death were obtained for 1730 patients $(95.6 \%)$. The mean follow-up was $34 \pm 15$ months. During follow-up, 376 patients died of any causes (59 in the DES group [10.2\%] and 317 in the BMS group [27.5\%], $P<0.001)$. The incidence of death of cardiac causes was $7.3 \%$ in the DES and $19.6 \%$ in the BMS group $(P<0.001)$.

In addition, the incidence of stroke $(3.1 \%$ versus $5.5 \%$, $P=0.037$ ) and coronary artery bypass surgery (DES $1.9 \%$ versus BMS 5.3\%, $P=0.002$ ) was lower in the DES group. The incidence of other adverse events during follow-up did not differ between the two groups (Table 2).

Kaplan-Meier analysis showed an increased cardiac mortality in the BMS group (Figure 1$)(P<0.001$ via log-rank test). According to the multivariate model, including the classic risk factors and additional risk factors with prognostic relevance for progression of CHD, DES was not superior to BMS (hazard ratio [HR] 0.996, 95\% confidence interval [CI] 0.455-2.182, $P=0.993$ ) (Table 3). In this "fully adjusted model," only glomerular filtration rate (GFR) was an independent predictor for cardiac mortality after PCI with stent implantation. Compared to a GFR $>90 \mathrm{~mL} / \mathrm{min}$, a GFR between 15 and $30 \mathrm{~mL} / \mathrm{min}$

Table 2 Adverse events during follow-up

\begin{tabular}{|c|c|c|c|c|}
\hline Variable & $\mathbf{N}$ & DES & BMS & $P$-value \\
\hline $\begin{array}{l}\text { Myocardial infarction } \\
(\mathrm{n}=1356)^{*}\end{array}$ & $85(6.3)$ & $26(5.1)$ & $59(7.0)$ & 0.155 \\
\hline Stroke $(\mathrm{n}=|38|)^{*}$ & $63(4.6)$ & $16(3.1)$ & $47(5.5)$ & 0.037 \\
\hline $\mathrm{ACB}(\mathrm{n}=1378)^{*}$ & $55(4.0)$ & $10(1.9)$ & $45(5.3)$ & 0.002 \\
\hline $\begin{array}{l}\text { Rehospitalization } \\
(\mathrm{n}=1340)^{*}\end{array}$ & $429(32.0)$ & $156(30.3)$ & $273(33.1)$ & 0.285 \\
\hline $\begin{array}{l}\text { Angiogram } \\
(\mathrm{n}=1339)^{*}\end{array}$ & $325(24.3)$ & $125(24.2)$ & $200(24.3)$ & 0.975 \\
\hline $\mathrm{PCl}(\mathrm{n}=1375)^{*}$ & 205 (I4.9) & $70(13.4)$ & $135(15.8)$ & 0.222 \\
\hline $\begin{array}{l}\text { Atrial fibrillation } \\
(\mathrm{n}=1379)^{*}\end{array}$ & $|2|(8.8)$ & $40(7.6)$ & 81 (9.5) & 0.248 \\
\hline $\begin{array}{l}\text { Thrombosis } \\
(\mathrm{n}=1376)^{*}\end{array}$ & $23(1.7)$ & $8(1.5)$ & $15(1.8)$ & 0.753 \\
\hline $\begin{array}{l}\text { Bleeding events } \\
(\mathrm{n}=1378)^{*}\end{array}$ & $39(2.8)$ & $14(2.7)$ & $25(2.9)$ & 0.796 \\
\hline Minor bleed & $14(1.0)$ & $6(1.1)$ & $8(0.9)$ & 0.700 \\
\hline Groin hematoma & I (0.I) & 0 & $\mathrm{I}(0 . \mathrm{I})$ & 0.435 \\
\hline Groin bleed & $13(0.9)$ & $5(1.0)$ & $8(0.9)$ & 0.965 \\
\hline Gastrointestinal bleed & $6(0.4)$ & $3(0.6)$ & $3(0.4)$ & 0.540 \\
\hline Intracranial bleed & $4(0.3)$ & 0 & $4(0.5)$ & 0.118 \\
\hline Embolism & I $(0.1)$ & 0 & I (0.I) & 0.435 \\
\hline Death $(n=1730)^{*}$ & $376(21.7)$ & $59(10.2)$ & $317(27.5)$ & $<0.001$ \\
\hline Cardiac death & $268(15.5)$ & $42(7.3)$ & $226(19.6)$ & $<0.001$ \\
\hline
\end{tabular}

Note: Variables are absolute number of events (percentages).

Abbreviations: DES, drug-eluting stent; $B M S$, bare metal stent; $A C B$, aortocoronary bypass; $\mathrm{PCl}$, percutaneous coronary intervention. 


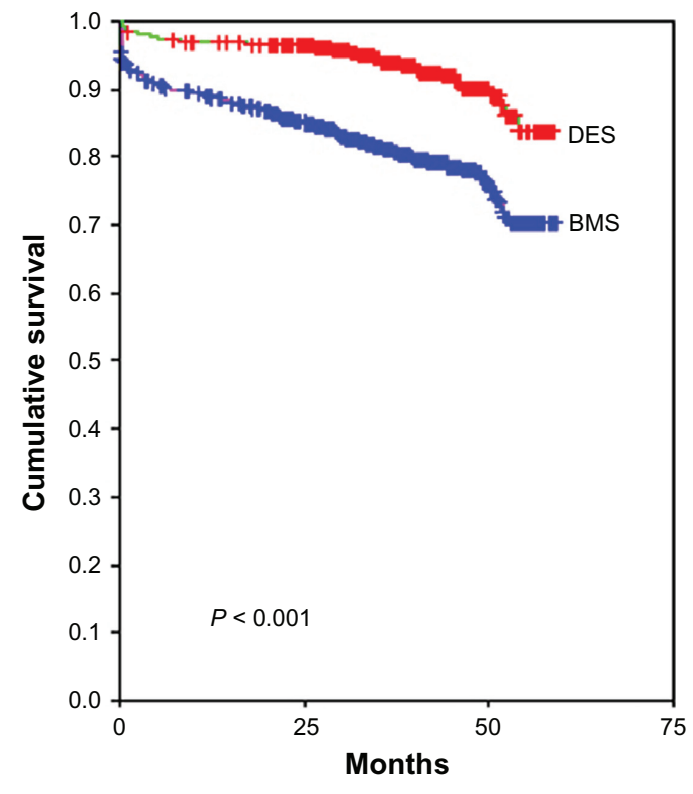

Figure I Kaplan-Meier analysis for cardiac death, DES versus BMS. Note: $P<0.00$ I by log rank test.

Abbreviations: DES, drug-eluting stent; BMS, bare-metal stent.

increased the HR to 6.788 (95\% CI 1.406-32.764, $P=0.017)$ and one of $<15 \mathrm{~mL} / \mathrm{min}$ to 7.011 (95\% CI 1.228-40.024, $P<0.028$ ), respectively (see Table 3 ).

\section{Discussion}

After being introduced into daily clinical practice, the use of DES in PCI increased until several papers reported concerns

Table 3 Multivariate Cox regression analysis

\begin{tabular}{lllll}
\hline & HR & Lower Cl & Upper Cl & P-value \\
\hline DES & 0.996 & 0.455 & 2.182 & 0.993 \\
Diabetes mellitus & 1.522 & 0.737 & 3.142 & 0.256 \\
Family history & 1.216 & 0.550 & 2.686 & 0.630 \\
Current smoker & 1.034 & 0.414 & 2.583 & 0.944 \\
Male & 1.247 & 0.536 & 2.900 & 0.608 \\
Hypertension & 1.050 & 0.442 & 2.491 & 0.912 \\
Hyperlipidemia & 1.348 & 0.570 & 3.187 & 0.496 \\
Age & 1.034 & 0.987 & 1.084 & 0.158 \\
LDL cholesterol & 1.037 & 0.798 & 1.443 & 0.642 \\
CRP & 1.001 & 0.993 & 1.010 & 0.787 \\
Hb $>$ Ref & 0.551 & 0.267 & 1.140 & 0.108 \\
LVEF $>50 \%$ & 0.537 & 0.265 & 1.091 & 0.086 \\
GFR & & & & 0.048 \\
GFR $<15 *$ & 7.011 & 1.228 & 40.024 & 0.028 \\
GFR I5-30* & 6.788 & 1.406 & 32.764 & 0.017 \\
GFR 30-60* & 1.801 & 0.613 & 5.294 & 0.285 \\
GFR 60-90* & 1.190 & 0.454 & 3.118 & 0.723 \\
\hline Notes: &
\end{tabular}

Notes: *Compared to preserved renal function. Values in SI units.

Abbreviations: HR, hazard ratio; DES, drug-eluting stent; LDL, low density lipoprotein CRP, C-reactive protein; $\mathrm{Hb}>$ Ref, hemoglobin above local level of normal; LVEF, left ventricular ejection fraction; GFR, glomerular filtration rate. about the long-term safety of these stents., ${ }^{9,10,14}$ Findings from various registries and meta-analyses showed an increase in all-cause mortality and the rate of major cardiovascular events $^{9,15}$ after DES implantation as compared with BMStreated patients. The aim of the present study was to compare mortality in an unselected patient population undergoing PCI with DES versus BMS implantation.

As described in the results section, the two groups in part significantly differed concerning the prevalence of cardiovascular risk factors (current smoking, diabetes mellitus, hypertension, hyperlipidemia, and positive family history). Also regarding the number of diseased vessels and the indication for PCI (ie, SAP, UAP, NSTEMI, and STEMI), significant differences can be observed. Patients presenting with SAP or UAP or 1-vessel-disease more often received DES, whereas patients suffering from STEMI or multivessel disease more often received BMS. These differences can be explained by the indications given in the revascularization guidelines. ${ }^{7}$ Meanwhile, current guidelines give a wider range of indications for the use of DES in more complex lesions and patient subsets. ${ }^{16}$

According to univariate analysis, DES are associated with an improved survival compared with BMS $(P<0.001)$ (Figure 1). However, in multivariate Cox regression analyses that include classic risk factors and further prognostic variables, use of DES completely lost its prognostic value. Also hemoglobin level, age, diabetes mellitus, and left ventricular ejection fraction, which are well known predictors for worse outcome of CHD patients, were not independently associated with the primary endpoint. In this model, the only independent predictor for cardiac mortality after PCI with stent implantation was impaired renal function. The authors conclude therefore that in a routine setting DES and BMS implantation are equally safe in terms of the occurrence of death of cardiac causes in the long term.

The findings of this present study are partly in line with recently published data on the safety of DES in the long and short term. Randomized studies taking diabetes mellitus, myocardial infarction, and multivessel disease as inclusion criteria $^{17-21}$ show encouraging results for the use of DES in these patient populations.

In patients with impaired renal function, systemic changes such as chronic inflammation, oxidative stress, anemia, a procoagulative milieu and endothelial dysfunction promote the progression of atherosclerotic changes and therefore also count as cardiovascular risk factors. ${ }^{22-24}$ Studies dealing with the impact of DES compared to BMS 
on the outcome in patients with renal impairment showed that the benefit of DES implantation depends on the degree of renal impairment. Whereas patients with normal renal function or mildly impaired renal function (ie, creatinine clearance $>60 \mathrm{~mL} / \mathrm{min}$ and $40[30]-60 \mathrm{~mL} / \mathrm{min}$, respectively) profit from DES implantation, ${ }^{25-28}$ this advantage can no longer be seen in patients with moderate or severe renal impairment ( $\mathrm{CrCl} 15-30 \mathrm{~mL} / \mathrm{min}$ and $<15 \mathrm{~mL} / \mathrm{min}$, respectively). The advantages for DES are mainly driven by a lower rate of revascularization (target vessel revascularization and target lesion revascularization), whereas no advantage concerning the occurrence of major adverse cardiac events, including cardiac death or death from any cause, was found. The fact that in this present study, impaired renal function was the only independent predictor in the multivariate model for worse outcome in patients after PCI with stent implantation emphasizes the influence of renal insufficiency on the progression of CHD (see Table 3).

Patients who suffer myocardial infarction (STEMI) comprise a high-mortality population. The use of stents is considered standard treatment in these patients. Nevertheless, the use of DES under these circumstances is the subject of controversial discussion. Recently published results of randomized controlled trials included 300-700 patients and evaluated angiographic and clinical events 9 months and 12 months after PCI, respectively. ${ }^{19,20,29,30}$ Most of them concluded that DES is safe in STEMI and decreases the rate of re-interventions, but they did not find any advantage for DES concerning death or recurrent myocardial infarction. In contrast to these findings the results of observational studies which covered a follow-up period of 30 days up to 2 years in "real-world" settings varied. They ranged from a significantly increased risk-adjusted mortality in patients treated with $\mathrm{DES}^{31}$ over comparable outcomes regarding long-term mortality ${ }^{32}$ to a lower risk-adjusted mortality for DES. ${ }^{33,34}$

Among the patients in this present study, 501 presented with acute myocardial infarction with ST-segment elevation. Of them, 126 were treated with DES and 375 with BMS. When applying univariate Kaplan-Meier analysis with log-rank test, DES was an independent factor concerning cardiac mortality $(P=0.005)$. In multivariate analysis including the abovementioned prognostically relevant factors, DES was no longer an independent factor (HR 0.114, 95\% CI 0.007-1.805, $P=0.123$; data not shown in the results section). However, the use of DES in the "real-world" patient collective was not linked to poorer survival.

\section{Conclusion}

Treatment of patients with DES is safe in the long term, also in the subgroup of patients presenting with STEMI; however, it is not superior to BMS treatment.

\section{Limitation}

As this study represents the results of "real-life" practice, the choice of stent type was up to the interventional cardiologist based on national and international guidelines and recommendations. Thus, a limitation of this study is the smaller sample size of patients treated with DES in comparison to patients treated with BMS.

\section{Disclosure}

The authors report no conflicts of interest in this work.

\section{References}

1. Serruys P, de Jaegere P, Kiemeneij F, et al. A comparison of balloonexpandable-stent implantation with balloon angioplasty in patients with coronary artery disease. Benestent Study Group. N Engl J Med. 1994; 331(8):489-495.

2. Fischman D, Leon M, Baim D, et al. A randomized comparison of coronary-stent placement and balloon angioplasty in the treatment of coronary artery disease. $N$ Engl J Med. 1994;331:496-501.

3. Morice M, Serruys P, Sousa J, et al. A randomized comparison of a sirolimus-eluting stent with a standard stent for coronary revascularization. N Eng J Med. 2002;346(23):1773-1780.

4. Moses P, Leon M, Popma J, et al. Sirolimus-eluting stents versus standard stents in patients with stenosis in a native coronary artery. N Engl J Med. 2003;349(14):1315-1323.

5. Grube E, Silber S, Hauptmann K, et al. Six- and twelve-month results from a randomized, double-blind trial on a slow-release paclitaxel-eluting stent for de novo coronary lesions (TAXUS I). Circulation. 2003;107:38.

6. Serruys PW, Kutryk MJ, Ong AT. Coronary-artery stents. $N$ Engl J Med. 2006;(354):483-495.

7. Silber S, Albertsson P, Avilés F, et al. The task force for percutaneous coronary interventions of the European Society of Cardiology. Eur Heart J. 2005;26(8):804-847.

8. Grines C, Bonow R, Casey DJ, et al. Prevention of premature discontinuation of dual antiplatelet therapy in patients with coronary artery stents: a science advisory from the American Heart Association, American College of Cardiology, Society for Cardiovascular Angiography and Interventions, American College of Surgeons, and American Dental Association, with representation from the American College of Physicians. Circulation. 2007;115(6):813-818.

9. Lagerquist B, James S, Stenestrand U, Lindbäck J, Nilsson T, Wallentin L. Long-term outcomes with drug-eluting stents versus bare-metal stents in Sweden. N Engl J Med. 2007;356(10):1009-1019.

10. Camenzind E, Steg G, Wijns W. Stent thrombosis late after implantation of first-generation drug-eluting stents: a cause for concern. Circulation. 2007;115:1440-1455.

11. Pfisterer M, Brunner-LaRocca H, Buser P, et al. Late clinical events after clopidogrel discontinuation may limit the benefit of drug-eluting stents: an observational study of drug-eluting versus bare-metal stents. J Am Coll Cardiol. 2006;48(12):2584-2591.

12. Nikolsky E, Aymong E, Halkin A, et al. Impact of anemia in patients with acute myocardial infarction undergoing primary percutaneous coronary intervention: analysis from the Controlled Abciximab and Device Investigation to Lower Late Angioplasty Complications (CADILLAC) Trial. J Am Coll Cardiol. 2004;44(3):547-553. 
13. Halkin A, Singh M, Nikolsly E, et al. Prediction of Mortality After Primary Percutaneous Coronary Intervention for Acute Myocardial Infarction: The CADILLAC risk score. JAm Coll Cardiol. 2005;45(9): 1397-1405.

14. Daemen J, Wenaweser P, Tsuchida K, et al. Early and late coronary stent thrombosis of sirolimus-eluting and paclitaxel-eluting stents in routine clinical practice: data from a large two-institutional cohort study. Lancet. 2007;369(9562):667-678.

15. Nordmann A, Briel M, Bucher H. Mortality in randomized controlled trials comparing drug-eluting vs bare metal stents in coronary artery disease: a meta-analysis. Eur Heart J. 2006;27(23):2784-2814.

16. Wijns W, Kolh P, Danchin N, et al. Guidelines on myocardial revascularization. Eur Heart J. 2010;31:2501-2555.

17. Maresta A, Varani E, Balducelli M, et al. Comparison of effectiveness and safety of sirolimus-eluting stents versus bare-metal stents in patients with diabetes mellitus (from the Italian Multicenter Randomized DESSERT Study). Am J Cardiol. 2008;101(11):1560-1566.

18. Baumgart D, Klauss V, Hartmann F, et al. One-year results of the SCORPIUS study: a German multicenter investigation on the effectiveness of sirolimus-eluting stents in diabetic patients. J Am Coll Cardiol. 2007;50(17):1627-1634.

19. Spaulding C, Henry P, Teiger E, et al. Sirolimus-eluting versus uncoated stents in acute myocardial infarction. $N$ Engl J Med. 2006;355(11): 1093-1104.

20. Laarman G, Suttorp MJ, Dirksen MT, et al. Paclitaxel-eluting versus uncoated stents in primary percutaneous coronary intervention. $N$ Engl J Med. 2006;355(11):1105-1113.

21. Chechi T, Vittori G, Biondi Zoccai G, et al. Single-center randomized evaluation of paclitaxel-eluting versus conventional stent in acute myocardial infarction (SELECTION). J Interv Cardiol. 2007;20(4): 282-291.

22. Sarnak M, Levey A, Schoolwerth A, et al. Kidney disease as a risk factor for development of cardiovascular disease: a statement from the American Heart Association Councils on Kidney in Cardiovascular Disease, High Blood Pressure Research, Clinical Cardiology, and Epidemiology and Prevention. Circulation. 2008;108: 2154-2169.

23. Luft F. Renal disease as a risk factor for cardiovascular disease. Basic Res Cardiol. 2000;95(Suppl 1):I72-I76.
24. Gupta R, Birnbaum Y, Uretsky B. The renal patient with coronary artery disease: current concepts and dilemmas. J Am Coll Cardiol. 2004;44(7):1343-1353.

25. Kim B, Oh S, Jeon D, Yang J. Long-term clinical outcomes and stent thrombosis of sirolimus-eluting versus bare metal stents in patients with end-stage renal disease: results of Korean multicenter angioplasty team (KOMATE) Registry. J Interv Cardiol. 2009;(22):411-419.

26. Halkin A, Mehran R, Casey C, et al. Impact of moderate renal insufficiency on restenosis and adverse clinical events after paclitaxel-eluting and bare metal stent implantation: results from the TAXUS-IV Trial. Am Heart J. 2005;(150):1163-1170.

27. Aoyama T, Ishii H, Toriyama T, et al. Sirolimus-eluting stents vs bare metal stents for coronary intervention in Japanese patients with renal failure on hemodialysis. Circ J. 2008;(72):56-60.

28. Shaw J, Andrianopoulos N, Duffy S, et al. Renal impairment is an independent predictor of adverse events post coronary intervention in patients with and without drug-eluting stents. Cardiovasc Revasc Med. 2008;9(4):218-223.

29. van der Hoeven B, Liem S, Jukema J, et al. Sirolimus-eluting stents versus bare-metal stents in patients with ST-segment elevation myocardial infarction: 9-month angiographic and intravascular ultrasound results and 12-month clinical outcome results from the MISSION! Intervention Study. J Am Coll Cardiol. 2008;(51):618-626.

30. Valgimigli M, Percoco G, Malagutti P, et al. Tirofiban and sirolimuseluting stent vs abciximab and bare-metal stent for acute myocardial infarction: a randomized trial. JAMA. 2005;(293):2109-2117.

31. Steg P, Fox K, Eagle K, et al. Mortality following placement of drugeluting and bare-metal stents for ST-segment elevation acute myocardial infarction in the Global Registry of Acute Coronary Events. Eur Heart J. 2009;(30):321-329.

32. Lemos P, Saia F, Hofma S, et al. Short- and long-term clinical benefit of sirolimus-eluting stents compared to conventional bare stents for patients with acute myocardial infarction. J Am Coll Cardiol. 2004;(43):704-708.

33. Mauri L, Silbaugh T, Garg P, et al. Drug-eluting or bare-metal stents for acute myocardial infarction. N Engl J Med. 2008;(359):1330-1342.

34. Slottow T, Steinberg D, Roy P, et al. Drug-eluting stents are associated with similar cardiovascular outcomes when compared to bare metal stents in the setting of acute myocardial infarction. Cardiovasc Revasc Med. 2008;(9):24-28.
Vascular Health and Risk Management

\section{Publish your work in this journal}

Vascular Health and Risk Management is an international, peerreviewed journal of therapeutics and risk management, focusing on concise rapid reporting of clinical studies on the processes involved in the maintenance of vascular health; the monitoring, prevention and treatment of vascular disease and its sequelae; and the involvement of

\section{Dovepress}

metabolic disorders, particularly diabetes. This journal is indexed on PubMed Central and MedLine. The manuscript management system is completely online and includes a very quick and fair peer-review system, which is all easy to use. Visit http://www.dovepress.com/ testimonials.php to read real quotes from published authors. 